\title{
Cracking and Hydrocracking of Triglycerides for Renewable Liquid Fuels: Alternative Processes to Transesterification
}

\author{
Roger Fréty, ${ }^{*, a}$ Maria da Graça C. da Rocha, ${ }^{a}$ Soraia T. Brandão, ${ }^{a}$ Luiz A. M. Pontes, ${ }^{b}$ \\ Jose F. Padilha, ${ }^{b}$ Luiz E. P. Borges ${ }^{c}$ and Wilma A. Gonzalez ${ }^{c}$
}

\author{
anstituto de Química, Universidade Federal da Bahia, Campus de Ondina, 40170-290 Salvador-BA, Brazil \\ ${ }^{b}$ Universidade Salvador (PRPG), Campus STIEP, Rua José Peroba, 251, 41770-235 Salvador-BA, Brazil \\ ${ }^{c}$ Seção de Química, Instituto Militar de Engenharia, Praia Vermelha, 22290-270 Rio de Janeiro-RJ, Brazil
}

\begin{abstract}
Os processos industriais mais utilizados na produção de combustíveis líquidos semelhantes ao diesel usam catalisadores homogêneos básicos através das metanólise e etanólise de óleos tais como os de soja, canola, palma entre outros. Desse modo, se obtém o biodiesel. Por sua vez, transformações termo-catalíticas usando as facilidades existentes nas refinarias de petróleo são alternativas que merecem atenção devido a sua viabilidade econômica. De fato, três processos industriais já estão em funcionamento e novos projetos estão em fase final para comercialização. O presente trabalho analisa os experimentos já realizados por pesquisadores brasileiros nas áreas do craqueamento, do craqueamento catalítico e do hidrocraqueamento catalítico dos óleos vegetais puros ou modificados. A partir dos resultados descritos, são sugeridas novas direções destas pesquisas para os próximos anos.
\end{abstract}

The most used industrial processes for the production of liquid fuels like diesel type are based on the methanolysis and ethanolysis of various oil reactants, such as palm, soybean and rapeseed oils, in the presence of homogeneous base catalysts. However, thermal and catalytic transformations of vegetable oils using available reactors and industrial processes are possible alternatives and deserve attention. In fact, three industrial processes are operating and new projects are announced. The present work analyses the experimental studies performed up to now by Brazilian researchers in the field of cracking, catalytic cracking and hydrocracking of pure or modified vegetable oils. From the published results, some research areas for the near future are suggested.

Keywords: vegetable oils, cracking, hydrocracking, catalysis

\section{Introduction}

Although their limited share in liquid fuels today, renewable sources coming from biomass are expected to play an important role in some regional energy matrixes. In fact, supplying isolated areas with petroleum fuels may sometimes appear as an uneconomical choice. Furthermore, new technical solutions can be prepared to face periods of political or economic crisis and to upgrade the standard of living of small farmers. The local production of liquid fuel presents an interesting alternative to transportation and stocking of traditional liquid fuels, such as gasoline, diesel and even kerosene. Nowadays, some people consume a quarter of fuel tank in their car just go to a fuel station and

\footnotetext{
*e-mail: frety@unifacs.br
}

back home. This added to the fact that it is expensive to feed, control and maintain isolated fuel stations is surpassing the limits of declining energetic resources.

In numerous regions, a fraction of agriculture production is used to generate renewable fuels with the use of simple chemical/biochemical transformations. In Brazil, ethanol produced from sugar cane is a good example. Besides the production of ethanol, used alone or mixed with gasoline for family cars, Brazil should be able to lead world progress in the production of liquid fuels for trucks, boats and local electricity generators, because of its large collection of native and cultivated vegetable oil sources, as well as other biomass and animal resources to feed processes of heavy liquid fuel production. The country would therefore be able to strengthen its capacity to elaborate renewable liquid fuels, either of second or third generation. 
As far as triglyceride transformations are concerned, numerous studies are being carried out by researchers from universities and technological centers in all Brazilian states.

Currently, these studies are mainly focused on the transesterification of vegetable oils and animal fats and/ or the esterification of fatty acids issued from the refining of these feeds. Transesterification is generally conducted with alcohols such as methanol and ethanol, in the presence of base homogeneous catalysts. Esterification, with the same alcohols, is conducted in the presence of acidic catalysts. Both reactions generate what is known as biodiesel (a consultation to the CNPq/Lattes database performed on October $30^{\text {th }}, 2010$, revealed that $2950 \mathrm{PhDs}$ and 4909 non PhDs used the word "biodiesel" in their CV; the $\mathrm{CNPq} / \mathrm{Lattes}$ database contains information concerning the activities of the Brazilian scientists). Various analyses of the biofuel transformations, focusing mainly on biodiesel, have been written in recent years by Brazilian scientists. ${ }^{1-7}$ Although biodiesel is well accepted, there is a need to perform important purification of both the final biodiesel and the major reaction by-product of the transesterification: glycerol. These purification steps may have an important environmental impact.

The studies into triglycerides pyrolysis, cracking and hydrocracking, which started in Brazil at the end of the 1970s, did not develop as much as transesterification. However, at a national and international industrial level considerable attention is now being given to such thermal transformations. ${ }^{8-12}$

The present work aims to review the published results obtained by Brazilian researchers in the field of cracking and hydrocracking of vegetable oils, and attempts to analyze the possibilities of these thermochemical routes to produce biofuels. It must be said however that outside Brazil, considerable work on this subject exists. ${ }^{13,14}$

\section{The First Steps in Brazil}

As already mentioned in various Brazilian reviews ${ }^{1-7}$ about the preparation of liquid fuels from triglycerides (or by-products from their refining or use), Brazilian interest in this area started in the 1970s, when the PROALCOOL program was initiated. In parallel to the need to obtain a liquid fuel (ethanol) for light vehicles, a need for liquid fuel for diesel engine vehicles rapidly appeared. The solution was to turn to vegetable oils and animal fats and the sources to produce them. The PROOLEO program was launched in the 1980s and some progress was achieved. However, the difficulty of getting large and regular volumes of feeds (unlike the case of ethanol) together with a lack of private investment in the fatty products field led to a rapid dissolution of the program and a decrease in public support. With the recent considerable increase in the soybean and other oil plant production in Brazil, together with the still good perspectives of further developments, the general situation has changed in recent years and a National Biodiesel program has started. The desired final products were considered to be the fatty acid methyl or ethyl esters, FAME or FAEE, whose properties are close to those of diesel fuel from petroleum. Therefore, major efforts have been devoted to the transesterification of triglycerides and to a lesser extent to fatty acid esterification with either methanol or ethanol.

However, the studies in triglycerides cracking initiated in Brazil at the end of the 1970s, never stopped, even though financial help was limited. Three examples of studies must be recalled at this point: $(i)$ the study of the thermocatalytic cracking at atmospheric pressure over alumina and magnesia catalysts using as raw material refined commercial soybean oil both before and after its prehydrogenation, ${ }^{15}$ (ii) the study of the hydrocracking of soybean and babassu oils at high pressure using supported metallic and sulfided catalysts, ${ }^{16,17}$ and (iii) the study of the thermocatalytic cracking of commercial soybean oil using $\mathrm{H}_{3} \mathrm{PO}_{4} / \mathrm{SiO}_{2}$ as the catalyst. ${ }^{18} \mathrm{In}$ all the three cases, reactions with model fatty acid molecules were also performed to improve the understanding of the complex chemistry of the transformation of vegetable oils. These studies will be presented later in some detail in this review that will successively examine studies on the pyrolysis of vegetable oils, on the thermocatalytic cracking of refined oils either pure or hydrogenated and on hydrocracking. It is important to state that in parallel to preceding studies, researchers at the Universidade Federal do Ceará (UFC, Ceará State, Brazil), besides their work on transesterification, were also working on the pyrolysis of triglycerides, ${ }^{19}$ and that some pilot units for the pyrolysis were developed at Centro de Pesquisas e Desenvolvimento (CEPED, Bahia State, Brazil) and Instituto Nacional de Tecnologia (INT, Rio de Janeiro State, Brazil).

\section{Pyrolysis}

Pyrolysis consists of thermally decomposing of a feed in the absence of oxygen or any other oxygenating compounds. Depending on the residence time of the reactant in the heated zone, one speaks of pyrolysis, quick pyrolysis and even flash pyrolysis, the latter one for residence times of the order of a few seconds. Applied to the case of vegetable oils and fats, pyrolysis produces materials resulting from simple cracking and from possible thermal reforming of the primary products to various secondary products, depending on the severity of the experimental conditions. 
Alencar et al. ${ }^{19}$ studied the pyrolysis of babassu (Orbignya martiana), piqui (Caryocar coriaceum) and palm (Elaeis guineensis) oils between 300 and 500 ${ }^{\circ} \mathrm{C}$, and that of oleic acid, one of the major moieties of the preceding feeds. Liquid yields of the order of 60 to $80 \%$ in volumes were obtained. Using CG-MS to analyze the liquid products, these authors found mainly saturated linear alkanes and 1-alkenes. Small quantities of cyclic hydrocarbons were also identified, mainly for the oils where lateral chains were rich in oleic acid. A reaction scheme was proposed. However, the absence of oxygenated compounds in the analyzed liquid products seems rather unexpected.

Using soybean oil, castor oil and palm oil, and pyrolysis temperatures between 350 and $400{ }^{\circ} \mathrm{C}$, Lima et al. ${ }^{20}$ obtained two types of liquid phases: an aqueous and an organic ones. The organic phase was distillated into four fractions: $\mathrm{F} 1<80^{\circ} \mathrm{C}, 80<\mathrm{F} 2<140{ }^{\circ} \mathrm{C}, 140<\mathrm{F} 3<200^{\circ} \mathrm{C}$ and $\mathrm{F} 4>200^{\circ} \mathrm{C}$. In general, the authors showed that the three vegetable oils gave similar liquid yields in the four liquid fractions. The F4 fraction, which would be expected to model a diesel-like mixture, was shown to be composed of olefins, paraffins, carboxylic acids and aldehydes, the quantity of the latter one being higher in the case of castor oil pyrolysis. The F4 fraction of castor oil pyrolysis also presented a higher concentration of compounds with a high chain length in both hydrocarbons (C15-C16) and fatty acids (C11-C12) compared with the two other oils (C11-C14) and (C7-C11) respectively. In the case of compounds obtained from the pyrolysis of soybean and palm oils, general fuel properties such as viscosity, cetane index and sulfur concentrations were within of the Brazilian standards for mineral diesel fuel. In the same study, the authors also showed that performing soybean oil pyrolysis at $400{ }^{\circ} \mathrm{C}$, through a catalyst bed with ZSM-5, induced further deoxygenation in the liquid products.

Oliveira et al. ${ }^{21}$ studied the combustion heats of various liquid fractions obtained from pyrolysis and transesterification of soybean and palm oils. As the present analysis is limited to the comparison between refined and pyrolysed oils, only selected results are presented in Table 1. Data in Table 1 show that the combustion heat of the pyrolysed product is lower than that of refined oil, the latter one being lower than that of the mineral diesel. This demonstrates, therefore, that for a given amount of energy, a larger amount of biofuel than mineral diesel is needed.
Doll et al..$^{22}$ studied other properties of biofuels obtained by pyrolysis, such as density, kinematic viscosity and surface tension. Pyrolysis was performed using refined soybean oil as well as the soybean soapstock (which is the product obtained by alkali extraction of the free fatty acids present in the soybean oil). These physical properties were studied either on the products directly obtained by pyrolysis at $350^{\circ} \mathrm{C}$ or on their mixtures with mineral diesel with either low (15 ppm) or high (50 ppm) sulfur content.

From all the measurements, the authors concluded that the liquid products obtained from the pyrolysis of both the refined soybean oil and the soybean soapstock can be used as additives to diesel fuel.

In a recent study, Suarez et al. ${ }^{23}$ showed interest in the lubricity of the F4 fraction of the liquid compounds obtained after the pyrolysis of soybean oil, compared to that of biodiesel. In their study, the pyrolysis conditions were similar to the preceding ones. ${ }^{20}$ The F4 fraction was mixed in various concentrations with mineral diesel, either rich $(50 \mathrm{ppm})$ or poor $(15 \mathrm{ppm})$ in sulfur. The variations in the density, kinematic and absolute viscosities were followed as a function of the compositions of the different mixtures. They concluded that the addition of bio-oil to mineral diesel either produced by transesterification or by pyrolysis substantially increases the lubricity of the liquid mixture, an interesting property for liquid fuels.

Santos et al. ${ }^{24}$ have used thermal cracking to upgrade agro-industrial residues. They pyrolysed soybean soapstock, beef tallow and poultry industry waste between 350 and $400{ }^{\circ} \mathrm{C}$ in a laboratory-made pyrolyser. After a first separation of the aqueous and organic liquid fractions, they further separated the organic fraction by distillation, as in their preceding study, ${ }^{20}$ and analyzed the main products contained in the diesel-like cut $\left(\mathrm{T}>200^{\circ} \mathrm{C}\right)$ by GC, GC-MS and IR spectroscopy. The amounts of organic fraction obtained were 6,31 and $56 \%$ and the yield of the diesel-like fraction in the organic fraction 20,56 and $51 \%$ for poultry waste, soapstock and beef tallow respectively. For the diesel-like fraction, the chromatograms obtained for the three different feeds were rather similar and showed a large amount of linear hydrocarbons (alkanes and alkenes) as well as oxygenated and even nitrogenated compounds, in smaller amounts. With the exception of poultry waste diesel-like fraction, which showed a high value in the copper corrosion test (ASTM D130), the other physicochemical properties (heating value, cetane index, carbon residue, viscosity, density) were within

Table 1. Combustion heat of crude and pyrolysed soybean and palm oils $\left(\mathrm{MJ} \mathrm{kg}^{-1}\right)$ (data from reference 21)

\begin{tabular}{lcccc}
\hline Diesel & Refined soybean oil & Refined palm oil & Pyrolysed soybean oil & Pyrolysed palm oil \\
\hline 46.7 & 41.9 & 41.3 & 39.7 & 38.9 \\
\hline
\end{tabular}


Brazilian diesel fuel specifications. The authors mentioned that work in progress to add Lewis acid catalysts to their pyrolysis system may allow better deoxygenation of their diesel-like fraction.

Worth mentioning at this point in the review are the studies of Figueiredo et al. ${ }^{25}$ These authors studied pyrolysis at rather low temperature $\left(380^{\circ} \mathrm{C}\right)$ of castor (Ricinus communis) seeds and the possibility of mixing the obtained liquids with mineral diesel fuel. During the experiments, they obtained four pyrolysis fractions, one of non condensable gases (10\%), one of pyrolysis oil $(50 \%)$, one of aqueous phase (12\%) and a residual heavy phase (28\%). The pyrolysis oil was further separated in three fractions by extraction with hexane, methanol and dichloromethane. These fractions were then analyzed by GC-MS and it was found that the hexane fraction was composed of alkanes, alkenes and aromatics. The other two fractions were rich in oxygenated compounds, some of them very complex, as oxygenated compounds were generated not only by the oil contained in the seeds, i.e. some $50 \mathrm{wt} . \%$, but also by some compounds resulting from a partial degradation of the lignin matrix of the seed. In a parallel study, Figueiredo et al. ${ }^{26}$ focused their work on a fine analysis of the products obtained from castor seed pyrolysis and compared the pyrolysis yields in liquid products with three other raw feeds: soybean seeds, soybean tort and Jatropha curcas tort. Fractions of the obtained biooils were also submitted to a number of characterizations in an attempt to understand their potential as an additive to mineral diesel. It was shown that by addition of up to $20 \%$ of these pyrolysed biooils in petroleum diesel, the resulting liquid fuels had physicochemical properties within the official standard values published by ANP (Agência Nacional de Petróleo, Gás Natural, Biocombustíveis: resolução No. 7 from March 19, 2008 (DOU 20.3.2008)).

Before finishing this part, it must be recalled that various Brazilian groups are developing pyrolysis units, either at laboratory scale, or at pilot plant scale, and are studying ways to upgrade the working parameters for better qualitative and quantitative production of liquid fuels.

The work of Wiggers et al. ${ }^{27}$ described the formation of liquid fractions starting from soybean oil pyrolysis in a pilot unit of quick pyrolysis. Experiments were performed at 450,525 and $600{ }^{\circ} \mathrm{C}$ with the occasional presence of steam. The steam was used both to clean the reactor at the end of an experiment and to allow the preheating of the reaction section before the soybean oil feeding. The obtained products were separated into three fractions by distillation: a residual fraction ( $\mathrm{RF}>\mathrm{C} 22$ ), a heavy oil fraction $(\mathrm{C} 11<\mathrm{HBO}<\mathrm{C} 22)$ and a light oil fraction $(\mathrm{C} 4<\mathrm{LBO}<\mathrm{C} 10)$, the heavy and light fractions simulating a range of compounds compatible with either diesel or gasoline, respectively. The best yields of liquid fractions were obtained at $525{ }^{\circ} \mathrm{C}$. Analyses of the liquid fractions showed that LBO contained alkanes, alkenes and aromatics up to dimethylbenzenes. The same types of hydrocarbon families were found in the HBO fraction with higher mean molecular weights. In $\mathrm{HBO}$, the analyses also showed the presence of untransformed fatty acids and of polialkylbenzenes. An energy balance showed that a fraction of the obtained products was sufficient to operate the plant. Other studies reported by the same research group used the preceding pilot plant to transform residual fish oil by quick pyrolysis. ${ }^{28,29}$ Using similar techniques of sampling and separation as before, GC, GC-MS, ${ }^{1} \mathrm{H}$ and ${ }^{13} \mathrm{C}$ NMR as analytical means, they were able to identify some $70 \%$ in volume of the LBO fraction. The main hydrocarbon families found were: olefins $(26.5 \% \mathrm{v} / \mathrm{v})$, aromatics $(17 \% \mathrm{v} / \mathrm{v})$, isoparaffins $(8.3 \% \mathrm{v} / \mathrm{v})$, naphthenes $(6.1 \% \mathrm{v} / \mathrm{v})$, $\mathrm{n}$-paraffins $(4.5 \% \mathrm{v} / \mathrm{v})$ and $\mathrm{C} 14+(5.3 \% \mathrm{v} / \mathrm{v})$. Traces of oxygenated compounds $(<0.1 \% \mathrm{v} / \mathrm{v})$ and unidentified compounds $(32.4 \% \mathrm{v} / \mathrm{v})$ closed the balance. These analyses were compared to the analysis of two gasolines, either with or without ethanol and a number of similarities were found. In the HBO fraction, alkenes, aromatics and non reacted fatty acids were identified. In order to reach the legal standards of Brazilian biofuels, the authors think that further studies are necessary, for example (i) optimization of the experimental conditions used for the pyrolysis, (ii) addition of catalyst to the process and (iii) consideration of the esterification of the heavy liquid fraction.

\section{Thermo-Catalytic Decomposition of Triglycerides}

Although the preceding studies have shown that the pyrolysis liquid products can be added in moderate quantities to mineral diesel, the high concentration of oxygenated compounds often found in these liquids may contribute to the emission of toxic compounds such as aldehydes during combustion in engines. Pyrolysis combined with catalysis appears therefore to be an option to promote a larger deoxygenation of the liquid fractions obtained. The first studies in Brazil appeared at the end of the 1970s.

Anjos et al. ${ }^{15,30}$ studied the thermocatalytic cracking of soybean oil at atmospheric pressure, between 300 and $500^{\circ} \mathrm{C}$, using $\eta$-alumina and magnesia as catalysts representative of acidic and base properties, respectively. Soybean oil was used in its commercial form (iodine index $=120$ ) or after an external pre-hydrogenation (iodine indexes $=60$ and 10). Figure 1 shows the reaction setup used at that 
time, whereas Figure 2 presents a global distribution of the products formed during the decomposition of the oil.

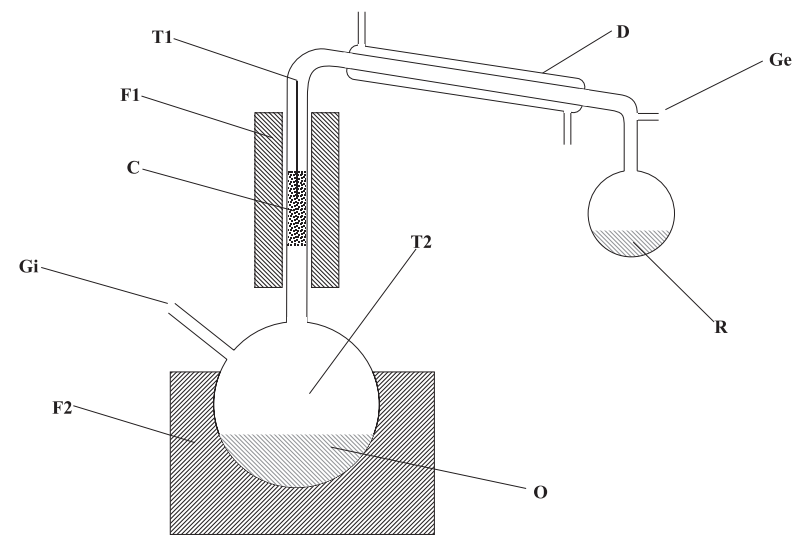

Figure 1. Apparatus for thermocatalytic decomposition of vegetable oil. $C$, catalysts; $D$, condenser; $F_{i}$, furnaces, $i=1,2 ; G_{i}$, gas inlet; $G_{e}$, gas exit; $\mathrm{O}$, soybean oil; $\mathrm{R}$, product collector; $\mathrm{T}_{\mathrm{i}}$, thermometer or thermocouple, $\mathrm{i}=1,2$ (adapted from reference 15, with kind permission of Elsevier).

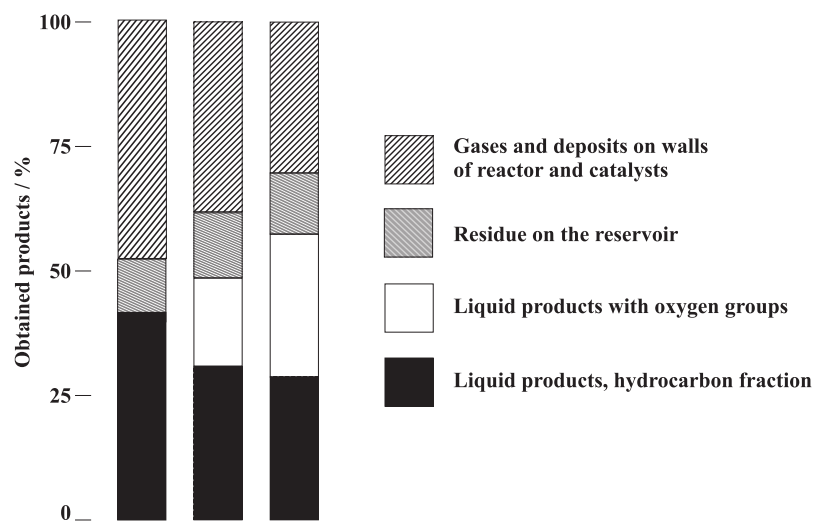

Figure 2. Influence of the saturation degree of soybean oil on the distribution of products; cracking by $\mathrm{Al}_{2} \mathrm{O}_{3}-\mathrm{S}$ at $400{ }^{\circ} \mathrm{C}$ (adapted from reference 15, with kind permission of Elsevier).

These products were separated into four different groups: gases and solid residues retained on the catalysts and in the pre-heating zone, residues in the feed reservoir, liquid compounds containing oxygen and liquid compounds free of oxygen in their structure. It was clear that after a pre-hydrogenation, the yield of hydrocarbons free of oxygen increased, all other experimental conditions being maintained. Chromatographic analyses of these hydrocarbons together with IR data showed a collection of compounds which were quite similar to those of a mineral diesel obtained from PETROBRAS (Petróleo Brasileiro S.A.). Table 2 shows some of the data obtained after thermocatalytic transformation of pre-hydrogenated soybean oil.

Thermo-catalytic cracking of model compounds, such as stearic and oleic acids, supported the above results as stearic acid with no $\mathrm{C}=\mathrm{C}$ bonds led to a larger liquid fraction
Table 2. Thermo-catalytic cracking of soybean oil after a pre-hydrogenation of the oil up to an iodine index of 10 (data from reference 15)

\begin{tabular}{lccc}
\hline Catalyst & $\begin{array}{c}\text { Temperature / } \\
{ }^{\circ} \mathrm{C}\end{array}$ & $\begin{array}{c}\text { Mass of liquid } \\
\text { products in relation } \\
\text { to the starting oil / } \\
\left(\mathrm{g} \mathrm{g}^{-1}\right)\end{array}$ & $\begin{array}{c}\text { Residues of } \\
\text { starting oil / } \\
\left(\mathrm{g} \mathrm{g}^{-1}\right)\end{array}$ \\
\hline No catalyst & 400 & 0.55 & - \\
Alumina & 300 & $0.44^{\mathrm{a}}$ & 0.10 \\
Alumina & 400 & $0.41^{\mathrm{a}}$ & 0.10 \\
Alumina & 500 & 0.39 & 0.10 \\
Magnesia & 300 & 0.46 & 0.10 \\
Magnesia & 400 & 0.44 & 0.07 \\
Magnesia & 500 & $0.42^{\mathrm{a}}$ & 0.08 \\
\hline
\end{tabular}

aReferred to a liquid fraction free of oxygen, as seen by IR analyses; ${ }^{b}$ residues represent the mass of oil residues present in the oil reservoir when the reaction was stopped and polymeric compounds deposited on the reactor wall and on the catalyst.

and a lower residual acidity than oleic acid, i.e. a better quality liquid product.

In the same period, in order to simplify the global process and suppress the pre-hydrogenation step, thermocatalytic decomposition of vegetable oils using solid acid catalysts with limited acidic strength was also considered. Catalysts with medium acidity strength were expected to limit the secondary reactions of the primary cracked products, such as deeper cracking, isomerisation and/or aromatization. These types of catalysts were also thought to show less deactivation. Catalysts based on $\mathrm{H}_{3} \mathrm{PO}_{4}$ supported on silica of various origins have been prepared and evaluated. Although the origin of silica led to significant differences in the catalytic results, liquid yields in linear saturated hydrocarbons were generally equal or better than those obtained with alumina and pre-hydrogenated soybean oil. ${ }^{18}$ At that time however, the difficulties in fully characterization of these interesting catalysts and their behavior led some of the aforementioned researchers to focus their studies more on general screening of catalysts, on experimental setup development and on the influence of the oil feed. ${ }^{5,6}$ In fact, they used not only soybean oil, but also babassu oil, Jatropha curcas oil, as well as model stearic and oleic fatty acids. Commercial catalysts, some of them obtained from PETROBRAS/CENPES (Centro de Pesquisas e Desenvolvimento Leopoldo Américo Miguez de Mello da PETROBRAS), such as $\gamma$-alumina, silica, $\mathrm{Ni}-\mathrm{W} /$ mordenite, $\mathrm{Y}$ and $\mathrm{NH}_{4} \mathrm{Y}$ zeolites, and catalysts prepared in the laboratory, such as transition alumina, niobium oxide, titanium oxide, either pure or modified by impregnation with metals (Ni/alumina, W/alumina) or with acidity promoters such as $\mathrm{TiO}_{2} / \mathrm{SO}_{4}, \mathrm{SiO}_{2} / \mathrm{SO}_{4}, \mathrm{Nb}_{2} \mathrm{O}_{5} / \mathrm{PO}_{4}$, $\mathrm{SiO}_{2} / \mathrm{BO}_{3}, \mathrm{AlCl}_{3} / \mathrm{SiO}_{2}, \mathrm{ZnCl}_{2} / \mathrm{SiO}_{2}, \mathrm{CdCl}_{2} / \mathrm{SiO}_{2}$, were used 
in reactors with different geometries. Most of the results obtained have already been presented. ${ }^{5,6}$ Tables 3, 4 and 5 show selected results of these data. ${ }^{5,6,18}$

The presence of phosphoric acid, either supported on activated carbon or on silica, leads to liquid products with low residual acidity, implying a quasi total disappearance of the fatty acids which are formed in the absence of such active catalysts. ${ }^{18}$ Although activated carbon gave very good results in terms of liquid quality, such a support did not appear in further publications: this point should be corrected in the future. It is interesting to note that the results obtained with phosphoric acid supported on mordenite did not lead to good quality liquid products. Rapid poisoning and deactivation of the catalyst are probably the reason for this.

Table 3. Product distributions of reaction: influence of $\mathrm{H}_{3} \mathrm{PO}_{4}$ impregnated onto different supports in the thermocatalytic cracking of soybean oil at $400{ }^{\circ} \mathrm{C}$ in a batch reactor under reflux conditions (data from reference 6)

\begin{tabular}{lcc}
\hline Catalyst & Liquid / \% & Acidity index \\
\hline No catalyst & 92 & 58 \\
$\mathrm{H}_{3} \mathrm{PO}_{4} /$ activated carbon & 53 & 1.7 \\
$\mathrm{H}_{3} \mathrm{PO}_{4} / \mathrm{SiO}_{2}$ & 74 & 5.0 \\
$\mathrm{H}_{3} \mathrm{PO}_{4} /$ mordenite & 72 & 40.4 \\
\hline
\end{tabular}

Table 4 presents some data obtained with two different vegetable oils using $\mathrm{MoO}_{3} / \mathrm{Al}_{2} \mathrm{O}_{3}$ catalysts. $^{5}$

It can be seen from the data in Table 4 that the oil transformations in the presence of Mo/alumina catalyst led to a higher content of saturated hydrocarbons, as well as to a lower acidity index when compared with the results obtained without catalyst. The higher liquid weight in the absence of catalyst is simply a result of the condensation of fatty acids that did not undergo transformation in the reactive zone before reaching the condenser. The differences observed with both oils probably reflect the main differences in oil composition, soybean oil showing initially less saturated fatty acid moieties and higher length of fatty acid chains than Jatropha curcas oil. These properties induce a better

Table 4. Product distributions of reaction: thermocatalytic decomposition at $410^{\circ} \mathrm{C}$ of soybean and Jatropha curcas oils in a continuous flow reactor (data from reference 6)

\begin{tabular}{lcccc}
\hline Oil feed & Catalyst & $\begin{array}{c}\text { Liquid / } \\
\text { wt.\% }\end{array}$ & $\begin{array}{c}\text { Acidity } \\
\text { index }\end{array}$ & $\begin{array}{c}\text { Saturated } \\
\text { hydrocarbons / } \\
\text { wt.\% }\end{array}$ \\
\hline Soybean & no & 85 & 91 & $<10$ \\
Jatropha curcas & no & 69 & 53 & $<10$ \\
Soybean & Mo/alumina & 68 & 25 & 39 \\
Jatropha curcas & Mo/alumina & 50 & 14 & 51 \\
\hline
\end{tabular}

liquid yield and a lower quantity of saturated hydrocarbons. Experimental conditions adapted to each type of oil feed would probably limit the differences in the quality of the obtained products.

Table 5 shows the role of acidity during the thermocatalytic decomposition of soybean oil.

From the data presented in Table 5, different ideas can be collected, although the experimental conditions are far from optimal. Both Lewis and Brønsted acidic solids led to better properties in the liquid products issued from the thermocatalytic decomposition of the soybean oil. ${ }^{6}$ Although limited in quality, a trend appears when comparing the production of saturated linear hydrocarbons and the probable acid strength of the solid catalysts, estimated by the pKa in the case of Brønsted acid samples and through the FriedelCraft catalytic activity in the case of Lewis supported compounds. However, such a comparison should be regarded with caution: in the case of Lewis supported acids, vegetable oil thermocatalytic cracking and Friedel Craft reactions occur in very different conditions of temperature and of oxygenated compound concentration. There is also some difficulty in the case of supported Brønsted species, as part of the acid sites can be modified during the reaction process due to water traces resulting from fatty acid decomposition, and also because pKa values are estimated at ambient temperature in water solvent and not at $350^{\circ} \mathrm{C}$ in an organic medium. In fact, trying to explain the properties of such working catalysts by characterizations in quite different conditions does not reflect reality. The situation is further complicated by the fact that a number of transformations may occur on the present catalysts during the heating from room temperature to the working one. The difficulty in characterizing the catalysts at the end of the run does not allow very representative correlations. However, it remains that some supports modified by impregnation with phosphoric acid are very efficient in promoting the thermocatalytic decomposition of vegetable oils towards saturated linear hydrocarbons, very similar to diesel components.

Table 5. Thermo-catalytic cracking of refined soybean oil at $350^{\circ} \mathrm{C}$ in a continuous flow reactor (data from reference 6)

\begin{tabular}{lcc}
\hline Catalyst & $\begin{array}{c}\text { Acidity present in the } \\
\text { liquid product / } \%\end{array}$ & $\begin{array}{c}\text { Saturated linear } \\
\text { hydrocarbons / \% }\end{array}$ \\
\hline $\mathrm{AlCl}_{3} / \mathrm{SiO}_{2}$ & 58 & 33 \\
$\mathrm{ZnCl}_{2} / \mathrm{SiO}_{2}$ & 53 & 42 \\
$\mathrm{CdCl}_{2} / \mathrm{SiO}_{2}$ & 58 & 37 \\
$\mathrm{SiO}_{2} \mathrm{Davisil}$ & 83 & 27 \\
$\mathrm{H}_{2} \mathrm{SO}_{4} / \mathrm{SiO}_{2}$ & 78 & 29 \\
$\mathrm{H}_{3} \mathrm{BO}_{3} / \mathrm{SiO}_{2}$ & 72 & 38 \\
$\mathrm{H}_{3} \mathrm{PO}_{4} / \mathrm{SiO}_{2}$ & 21 & 51 \\
\hline
\end{tabular}


Studies using different types of zeolites were performed by Santos et al..$^{31}$ In this case, the proposed objective was to obtain branched hydrocarbons isomers and aromatics able to upgrade some properties of gasoline. ${ }^{28}$ The oil feed studied was a commercial soybean oil and the catalytic transformations were performed between 400 and $500{ }^{\circ} \mathrm{C}$. Samples of $1 \mathrm{~g}$ oil were injected over a catalyst bed of $1.5 \mathrm{~g}$, maintained at the reaction temperature and the liquid phase issued from the transformation collected in a low temperature flask before analysis. The gaseous fraction formed during the reaction was not analyzed. The main conclusion of this study was that Brønsted acidity, principally in the case of H-ZSM5 and USY catalysts, was a key property in the important formation of aromatics. Table 6 summarizes some of the data presented..$^{28}$

Table 6. Thermo-catalytic transformation of soybean oil performed at $400{ }^{\circ} \mathrm{C}$. The $\mathrm{I}_{\mathrm{B}} / \mathrm{I}_{\mathrm{L}}$ represents the ratio of Brønsted/Lewis sites as measured by adsorption of pyridine followed by IR spectroscopy (data from reference 31)

\begin{tabular}{lcccc}
\hline Catalyst & $\begin{array}{c}\text { C5-C12 } \\
\text { fraction }\end{array}$ & BTX fraction & $\begin{array}{c}\text { Aliphatic } \\
\text { fraction }\end{array}$ & $\mathrm{I}_{\mathrm{B}} / \mathrm{I}_{\mathrm{L}}$ \\
\hline $\mathrm{H} \mathrm{SiO}_{2}-\mathrm{Al}_{2} \mathrm{O}_{3}$ & 40 & - & 40 & - \\
H Mordenite & 11 & 6 & 5 & 0.4 \\
$\mathrm{H}$ ZSM5 & 79 & 73 & 6 & 2.8 \\
USY & 75 & 76 & - & 2.2 \\
\hline
\end{tabular}

The fraction C5-C12 represents the proportion of this group of compounds inside the total liquid fraction. The BTX (benzene, toluene and xylene fraction) represents the proportion of this class of compounds in the $\mathrm{C} 5-\mathrm{C} 12$ fraction. The aliphatic fraction is the complement of the BTX fraction to close the balance. Finally, the $I_{B} / I_{L}$ value gives the ratio between the intensity of the IR bands at 1550 and $1450 \mathrm{~cm}^{-1}$ respectively for adsorbed pyridine at ambient temperature. This ratio gives an idea of the relative numbers of Brønsted and Lewis acid sites in the original zeolite material.

Guerra et $a l .{ }^{32}$ studied the thermal decomposition of andiroba oil, Carapa guianensis in conditions comparable to those used by Santos et al. ${ }^{31}$ They used as solid catalysts a natural smectite-bearing clay from Pará State modified by pillaring with $\mathrm{Al}, \mathrm{Ti}$ and $\mathrm{Zr}$ species. They observed a good correlation between certain physical and chemical properties of their catalysts and the ratio $\mathrm{H}_{\text {aromatics }} / \mathrm{H}_{\text {aliphatics }}$ in the $\mathrm{C} 5-\mathrm{C} 12$ fraction obtained from the cracking of andiroba oil. This ratio, the measurement of the quantity of aromatics over aliphatics produced at the end of the reaction, varied linearly from 0.5 to 3.5 with increases in surface area, in microporous volume and in the interplanar distance between the smectite layers, as the result of pillaring. They also observed a linear relationship between the preceding ratio and the increase in the ratio $\mathrm{I}_{\mathrm{B}} / \mathrm{I}_{\mathrm{L}}$, measurement of the relative importance of Brønsted and Lewis acidity calculated from pyridine IR absorption bands as before. ${ }^{31}$

These two studies ${ }^{31,32}$ indicate that modification of acidity parameters in the catalysts used during the thermocatalytic transformation of vegetable oils is a way to change the selectivity of the transformation, either towards aliphatic or towards aromatic products, suggesting a reasonably good flexibility of the global reaction scheme.

In order to better understand the types of catalytic sites involved during the thermocatalytic transformation of vegetable oils, the thermal degradation of oleic acid, the model molecule for the main fraction of lateral chains in vegetable oils, such as soybean oil, was studied with specific solid catalysts. ${ }^{33,34}$

Reguera et al $^{33}$ studied the thermocatalytic degradation of oleic acid in a continuous flow reactor at $350{ }^{\circ} \mathrm{C}$. The used catalyst samples were based on niobium oxides, either pure or modified with phosphorus. The solid catalyst that showed the best results was $\mathrm{NbOPO}_{4}$, its acidity and porous volume being greater than that of all the other catalysts tested. With $\mathrm{NbOPO}_{4}$, the acidity of the liquid phase obtained after decomposition of the oleic acid decreased from $3.6 \mathrm{mmol} \mathrm{g}^{-1}$ liquid in the absence of the catalyst down to $0.7-0.9 \mathrm{mmol} \mathrm{g}^{-1}$ liquid . At the same time, the conversion degree of oleic acid, close to 3-5\% in the absence of catalyst, increased up to $75-80 \%$ in the presence of $\mathrm{NbOPO}_{4}$. It seems important to mention that compounds similar to mineral diesel, i.e. a C14-C18 fraction, were obtained in greater quantity (some $30 \%$ of the liquid fraction) with $\mathrm{NbOPO}_{4}$ when compared with other niobium catalysts of the study.

Some of the preceding authors also studied other catalysts in the thermocatalytic decomposition of oleic acid, more precisely alumina based catalysts, either pure or modified with $\mathrm{H}_{3} \mathrm{PO}_{4}{ }^{34}$ Experimental conditions were the same as above, in the case of reaction with niobium based catalysts. The results showed that the reaction provided two main fractions, one with a mean composition close to that of diesel fuel, the other heavier, showing potential as a bio-lubricant. As in the case of niobium based catalysts, the impregnation of the alumina with phosphoric acid favored deoxygenation reactions. The best results were obtained with an alumina support prepared in the laboratory and impregnated with $12 \mathrm{wt} . \% \mathrm{H}_{3} \mathrm{PO}_{4}$. In this case, the acidity of the liquid products was found to be in the range of 0.2-0.4 mmol g-1 and the conversion of oleic acid reached values higher than $95 \%$. By separating the products into three fractions, it was possible to obtain $27 \%$ of a fraction in the diesel range (C14-C18), a great fraction (70\%) of liquids of lubricant type (C18-C22) and traces of compounds with a 
greater length (>C23). The presence of hydrocarbons with a chain length higher than that of the fatty acid of the starting feed suggests a very complicated chemistry, implying multiple cracking, isomerization and polymerization, and not only decarboxylation. However, the authors mainly compared the results obtained with alumina to those obtained with niobium oxide. They reached the conclusion that as niobium was more acid than alumina it promoted the formation of lighter products. But further studies are necessary to explain the behavior of alumina-based catalysts, as the quantity of the lubricant fraction cannot simply result from some secondary reaction pathways. Finally, as pure alumina is much more active than niobium oxide, the improvement in the liquid quality resulting from the addition of phosphoric acid was less pronounced.

Comparable studies were also performed in other research groups in Brazil, mainly after the government decision to increase the importance of liquid fuels from renewable sources, more specifically from triglyceride feeds, in the transport energy matrix.

Prado and Antoniosi ${ }^{35}$ studied thermocatalytic cracking of soybean oil between 380 and $400^{\circ} \mathrm{C}$ on catalysts made of bauxite heat-treated at $500^{\circ} \mathrm{C}$ in air before use. The reaction was performed under reflux in 3 different setups, one of which is shown in Figure 3. Here the intensity of reflux was altered by modifying the geometry of the first condenser.

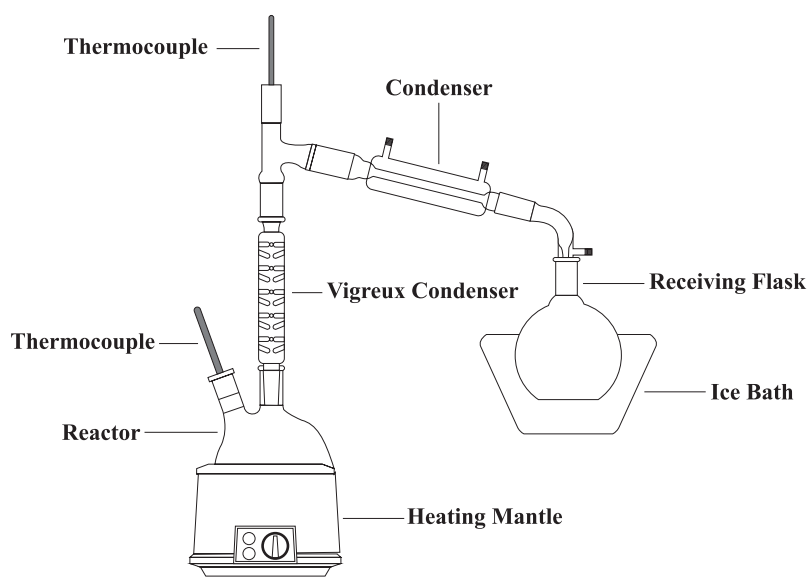

Figure 3. One of the pyrolysis setup used by Prado and Antoniosi ${ }^{35}$ for the thermocatalytic cracking of soybean oil. The reflux conditions of the reagents were modified by changing the geometry of the equipment at the level of the Vigreux condenser (adapted from reference 35, with kind permission of Elsevier).

Both the aqueous and organic liquid phases resulting from cracking were collected and separated by decantation before analysis. In these experiments, it appeared that better liquid yields were obtained when the reflux was limited. This is expected because a limited reflux implies a large quantity of fatty acids condensing in the collector without further transformation. Whereas the cracking performed without catalyst led to liquids with a high acid content, the presence of the catalysts led to a clear decrease in the acidity in the condensed liquid. This is in accordance with the positive role of the catalyst in helping deoxygenation of the fatty acids formed by pure thermal cracking, as seen in other results presented above. The authors considered that bauxite, besides being an inexpensive material, is a good catalyst. However, it should be remembered that bauxite may present many different compositions depending on its origin and probably cannot be used without undergoing well defined purification processes.

Brandão et $a l .{ }^{36}$ in a study essentially focused on the characterization of the initial state of their samples compared solid catalysts based on niobium oxides in three different processes: the transesterification of soybean oil, the thermocatalytic cracking of the soybean oil and the esterification of the fatty acids present in soybean oil. Looking simply at the results of thermocatalytic cracking, the authors observed that the modification of niobia by sulfuric and phosphoric acids led to a much higher production of both gaseous products and $\mathrm{F} 1$ fraction (fraction $\mathrm{F} 1$ distilled under $80^{\circ} \mathrm{C}$ ) in comparison with other niobium based catalysts. A pretreatment of niobia with nitric acid resulted in a significant increase in the surface area of the catalyst sample. However, this modification was unable to help in the formation of liquid products with characteristics correlating to the initial acidic properties of the catalyst. It is important to note that when the niobia catalyst was modified by phosphoric acid, not only lighter products were formed, but also the amount of $\mathrm{F} 4$ fraction, i.e. liquid compounds distilling above $200{ }^{\circ} \mathrm{C}$ increased. In the latter case, further analyses have shown that the $\mathrm{F} 4$ fraction contained a much higher amount of organic acids than when the reaction was performed without catalyst. Besides the presence of organic acids, other oxygenated compounds, such as acroleine and 2-propanone produced by secondary transformation of glycerol, were also detected. In this fraction too, potentially useful compounds, such as linear alkanes and alkenes, were present. In view of the results from the study of Brandão et al., ${ }^{36}$ doubts have arisen as to the general use of niobium based catalysts to obtain high amounts of diesel additives from soybean oil decomposition at temperatures between 350 and $400{ }^{\circ} \mathrm{C}$.

Quirino et al. ${ }^{37}$ cracked soybean oil between 350 and $400^{\circ} \mathrm{C}$, in the presence of catalysts based on $\mathrm{Zn}$ and on $\mathrm{Sn}$ oxides, co-precipitated with alumina. After separation of the aqueous and organic phases, and further distillation of the organic phase in four fractions F1, F2, F3 and F4, the authors observed that the presence of the catalysts during thermocatalytic cracking led to an increase in the yield 
of liquid products and to a decrease in the oxygenated compounds in the organic fraction. A catalyst with a composition $(\mathrm{SnO})_{1}(\mathrm{ZnO})_{1}\left(\mathrm{Al}_{2} \mathrm{O}_{3}\right)_{8}$, led to the best yield in the $\mathrm{F} 4$ fraction, i.e. the fraction with compounds comparing with petroleum diesel cut. In that study, it was not possible to establish a correlation between the liquid yields obtained and the specific surface area of the catalysts.

Although the study of Graça et $a l .^{38}$ is not directly connected to the thermocatalytic cracking of triglycerides, it may help in future biofuel strategies. The authors considered the cracking of selected oxygenated model compounds and described what could happen during the up-grading of third generation bio-fuels, i.e. bio-fuels directly obtained from raw materials and residues from agriculture and forestry, particularly rich in oxygenated species. Cracking was performed in a laboratory unit, in conditions similar to those used during fluid cracking operations (FCC). The tested catalysts were made with mixtures of a FCC equilibrium catalyst and ZSM-5 zeolite. The processed feed was a mixture of model compounds with petroleum gasoil. Acetic acid, hydroxyacetone and phenol were chosen as model compounds due to their different oxygenated functions. Their weight contents in the mixture were 6.4, 8.0 and $10.0 \%$, respectively. The authors showed that the added model compounds were decomposed to lighter products during the reaction. The cracking of the mixture increased the conversion of the gasoil and led to a decrease in carbon deposits on the catalyst. One of the conclusions of this study was that up to $10 \mathrm{wt} . \%$ in the mixture, the oxygenated compounds, with the exception of phenol, could be coprocessed with gasoil in a real FCC reactor. Although this study does not deal with triglycerides or products from their thermocatalytic cracking, it suggests that vegetable oils and fats and related compounds are able, within certain limits, to be co-processed with FCC feeds and to participate in the production of different families of liquid fuels.

From the works described in the preceding sections, it appears that pyrolysis and thermocatalytic transformations of triglycerides and related compounds may play a role in the formation of liquid fuels. However, in most of the experiments performed up to now, the hydrocarbons ready for use in transport fuels do not generally present yields much higher than some 50\% in weight, in comparison with the original feed. Two different directions may therefore be considered: ( $i$ ) the study of the possibility of refining the liquid compounds often rich in oxygen and unsaturated compounds and develop a particular chemistry able to upgrade the products of either thermal or thermocatalytic degradation completely, including the residues of the cracking, (ii) the simplification of the chemistry of raw vegetable oils, as they present very different properties when considering their degree of saturation, the length of fatty acid structural units, the possible presence of functional groups, added to the potential presence of very different types of impurities depending on the origin of the feed. A possible direction of the work appears in the initial studies of Anjos et al.,$^{15}$ where a pre-hydrogenation of soybean oil led to products with a lower degree of complexity and well comparable to mineral diesel.

\section{Hydrocracking}

Nunes et al. ${ }^{16}$ started studies into hydrocracking of soybean oil under high pressure conditions. The authors compared reaction processes with and without catalysts, and tested mono (oxides) and bi-functional catalysts (supported metals). Using Ru and Rh supported on silica, alumina and silica-alumina, and an initial hydrogen pressure of $c a .2$ to $3 \mathrm{MPa}$, they observed the hydrogenation of the soybean oil at around $200^{\circ} \mathrm{C}$ and the beginning of the hydrogenolysis below $400^{\circ} \mathrm{C}$. Gas phase analysis at the end of the run suggested the existence of both decarbonylation and decarboxylation reactions. The calculated yields in products, including gaseous products, were close to 83 wt.\% in the best case and the major organic group detected in the liquid products was saturated linear alkanes.

Gusmão et al. ${ }^{17}$ worked on the same research subject but changed the type of catalysts and increased the working pressure range. The hydrocracking of vegetable oils and fatty acids was performed in a batch reactor in the presence of hydrogen between 350 and $400{ }^{\circ} \mathrm{C}$. The chosen catalysts were $\mathrm{Ni} / \mathrm{SiO}_{2}$ with 8 wt. $\%$ metal and a sulfided $\mathrm{Ni}-\mathrm{Mo} / \gamma$-alumina with $3 \mathrm{wt} . \% \mathrm{Ni}$ and $14 \mathrm{wt} . \% \mathrm{Mo}$. In the case of $\mathrm{Ni} / \mathrm{SiO}_{2}$, the active phase was pre-reduced with pure hydrogen up to $400{ }^{\circ} \mathrm{C}$, passivated at room temperature and reduced again during the first steps of the reaction. The Ni-Mo catalysts were sulfided up to $500{ }^{\circ} \mathrm{C}$ with a mixture $\mathrm{H}_{2} / \mathrm{H}_{2} \mathrm{~S} 10 \%$ in volume, cooled down under helium and protected from air contact through an immersion in $\mathrm{n}$-hexane before feeding into the reactor. The starting reagents were commercial soybean oil and a babassu oil with mean compositions presented in Table 7. Both original oils showed a small quantity of sulfur, $4.5 \mathrm{ppm}$ for babassu oil and $5.0 \mathrm{ppm}$ for soybean oil.

Figure 4 shows the variations in pressure (initial hydrogen pressure $=4 \mathrm{MPa}$ ) and in temperature as a function of time. The temperature increase was maintained between 1 and $2{ }^{\circ} \mathrm{C} \mathrm{min}^{-1}$.

In Figure 4 it can be seen that the heating of the reactor up to $150^{\circ} \mathrm{C}$ led to a parallel increase in the reactor pressure, as normally expected when no transformation occurs. Between 150 and $200{ }^{\circ} \mathrm{C}$, the pressure dropped whereas 
Table 7. Composition in terms of fatty acids present in babassu and soybean oils, expressed as fatty acid moieties (FAi.j), where i represents the number of carbons in the lateral chain of the vegetable oil and $\mathrm{j}$ is the number of $\mathrm{C}=\mathrm{C}$ bonds (data from reference 17 )

\begin{tabular}{lccccccccc}
\hline Fatty acid & FA8.0 & FA10.0 & FA12.0 & FA14.0 & FA16.0 & FA18.0 & FA18.1 & FA18.2 & FA18.3 \\
\hline Babassu oil / (molar \%) & 4.6 & 6.0 & 42.5 & 16.1 & 9.7 & 3.6 & 14.0 & 3.5 & - \\
Soybean oil / (molar \%) & - & - & - & - & 15.0 & 3.5 & 21.7 & 54.0 & 5.8 \\
\hline
\end{tabular}

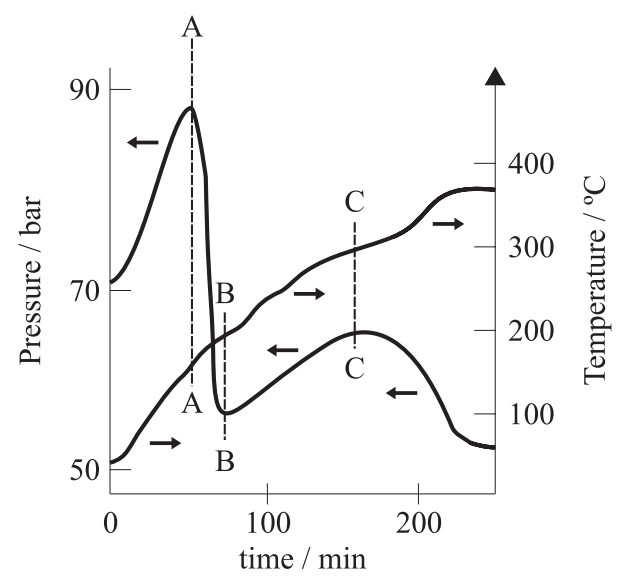

Figure 4. Evolution of the temperature and the gas pressure ( $1 \mathrm{bar}=0.1 \mathrm{MPa}$ ) during the hydrocracking of soybean oil, in the presence of $\mathrm{Ni} / \mathrm{SiO}_{2}$ as a function of the time (reprinted from reference 17 , with kind permission of Elsevier).

the temperature increased. The global pressure started to increase again when the temperature went from 200 up to $300{ }^{\circ} \mathrm{C}$. Between 300 and $400{ }^{\circ} \mathrm{C}$, a new increase in temperature led to a second decrease in the pressure in the reactor. Once $400{ }^{\circ} \mathrm{C}$ was reached, the pressure stabilized. The pressure drop between 150 and $200^{\circ} \mathrm{C}$ was attributed to the hydrogen consumption due to hydrogenation of the $\mathrm{C}=\mathrm{C}$ double bonds present in the starting soybean oil, which contains a great quantity of oleic, linoleic and linolenic moieties. A very limited consumption of hydrogen in this temperature range might also be due to the reduction of the passivated layers of nickel particles. Both hydrogenations are completed rather easily under the experimental conditions. The second pressure decrease in the reactor is attributed to more complex processes. It has been seen during the thermal degradation of vegetable oils that cracking of the fatty branch of the vegetable oil starts at temperatures close to $300{ }^{\circ} \mathrm{C}$. The same must have occurred in the present experimental conditions. However, in parallel to the separation of fatty acid moieties from the glycerol backbone, hydrogenation of a number of products and by-products occurred. In fact, at temperatures of $300^{\circ} \mathrm{C}$ and higher, the gaseous phase above the liquid phase showed the presence of products such as $\mathrm{CO}$, $\mathrm{CO}_{2}, \mathrm{H}_{2} \mathrm{O}$ and $\mathrm{CH}_{4}$, and also $\mathrm{C} 2, \mathrm{C} 3$ and $\mathrm{C} 4$ hydrocarbons. The oxygenated gaseous products probably result from three different types of decarbonylation, decarboxylation and deoxygenation reactions, whereas the saturated gases may be formed by hydrogenation of the glycerol entity after the liberation of fatty acid fragments, and/or further hydrogenolysis and reforming of these fragments. Methane would originate either from $\mathrm{CO}$ and $\mathrm{CO}_{2}$ hydrogenation, or from the complete hydrogenolysis of low molecular weight hydrocarbons.

In the experimental conditions used by Gusmão et al., ${ }^{17}$ liquid and gaseous phases in the reactor reached a global equilibrium before completion of the reaction. To displace the equilibrium and obtain an almost total conversion of the soybean oil, it was necessary to increase the hydrogen pressure up to $20 \mathrm{MPa}$, in the case of $\mathrm{Ni} / \mathrm{SiO}_{2}$ catalyst.

In the case of soybean oil hydrocracking on sulfided NiMo/alumina catalyst, the hydrogenation of the $\mathrm{C}=\mathrm{C}$ bonds occurred between 180 and $250^{\circ} \mathrm{C}$, in agreement with the fact that sulfided catalysts have a lower hydrogenation capacity than supported metal catalysts. However, decarboxylation, decarbonylation and deoxygenation reactions also started to take place around $300{ }^{\circ} \mathrm{C}$, as in the case of the metal catalyst. At $400{ }^{\circ} \mathrm{C}$, complete oil conversion required an increase in the hydrogen pressure up to $30 \mathrm{MPa}$. Obviously, the use of other reactors, like flow reactors, should allow complete oil transformation at lower hydrogen pressures. The catalytic transformation of oleic acid under similar conditions confirmed the two main steps of the process: hydrogenation followed by hydrocracking.

Figure 5 shows a GC analysis of the liquid obtained after hydrocracking of babassu oil in the presence of sulfided $\mathrm{Ni}-\mathrm{Mo} / \mathrm{alumina}$ catalyst. It appears that almost all peaks in the chromatogram are due to saturated linear alkanes. The selectivity towards these products was calculated to be almost $97 \%$ in relation to the oil feed. Whereas in vegetable oils, whose fatty acid fragments in general contain only even numbers of $\mathrm{C}$, it is important to note the existence of hydrocarbons with even and uneven $\mathrm{C}$ numbers, see Figure 5. With the exception of the couple C7-C8, hydrocarbons with an even number of $\mathrm{C}$ are quantitatively higher than their homologues containing an uneven $\mathrm{C}$ number. This implies that in the used experimental conditions, ${ }^{17}$ deoxygenation without $\mathrm{C}$ loss was more important than the addition of both decarboxylation and decarbonylation leading to the loss of the $\mathrm{C} 1$ carbon in the fatty acid fragments and the liberation of either $\mathrm{CO}_{2}$ or CO. It is therefore important to identify the catalyst 


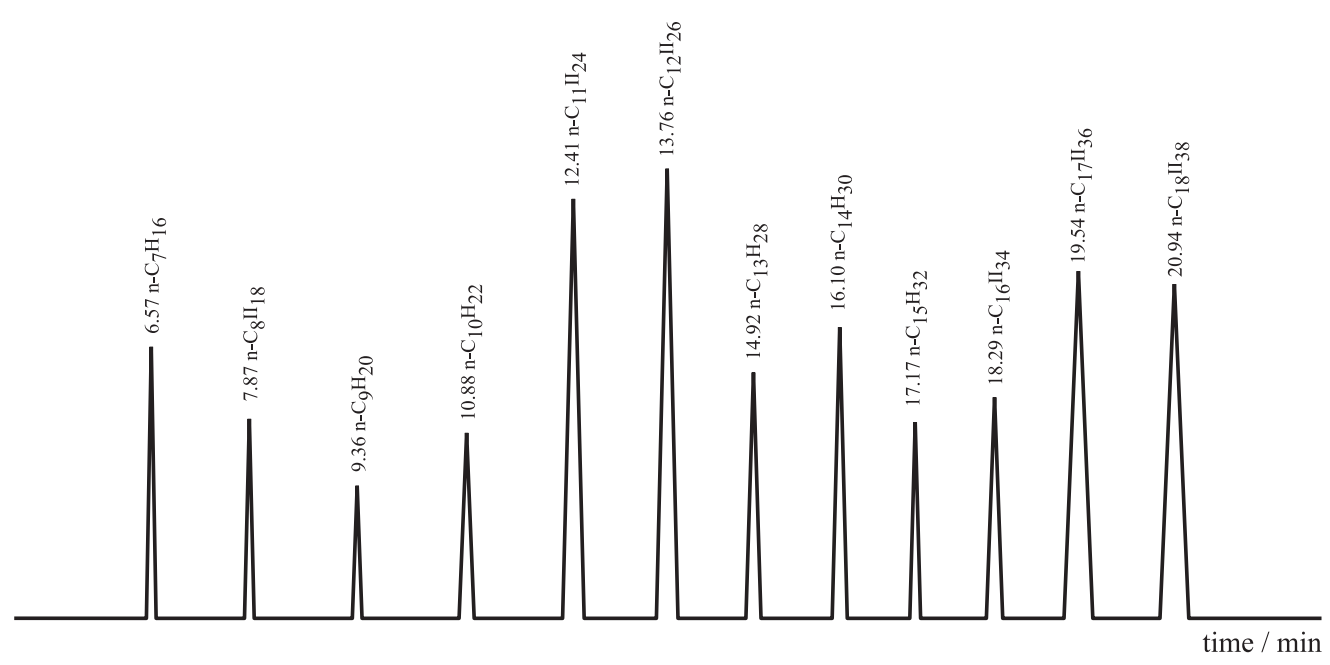

Figure 5. Chromatogram of babassu oil hydrocracking liquid products, at $633 \mathrm{~K}$, final $\mathrm{P}_{\mathrm{H} 2}=30 \mathrm{MPa}$ approximately, in the presence of sulfided $\mathrm{Ni}-\mathrm{Mo} / \gamma-\mathrm{Al}_{2} \mathrm{O}_{3}$ (adapted from reference 17, with kind permission of Elsevier).

properties which are better at promoting the selectivity of the cracking reaction towards reaction mechanisms with or without carbon loss. In reality, the deoxygenation without $C$ loss requires the removal of 2 oxygen atoms in the form of water, followed by hydrogen addition to the depleted $\mathrm{C}$, i.e. a much more hydrogen consuming process than cracking with the loss of one carbon in the form of $\mathrm{CO}_{2}$.

Other studies into hydrocracking were performed using different oil feeds. In one study, Amazonian oils such as Hevea brasiliensis and Virola sebifera were used as starting feed for hydrocracking process to form liquid hydrocarbons. ${ }^{39}$ In a second study, in order to better understand both the role of the fatty acid chain length and chain saturation, Rocha et $a l .^{40}$ also studied oil feeds from passion fruit (Passiflora edulis), tucuma (Astrycarium vulgaris), buriti (Mauritia flexuosa), babassu (Orbygnya martiana) and soybean.

In both studies, ${ }^{39,40}$ hydrocracking was performed with an industrial $\mathrm{Ni}-\mathrm{Mo} / \gamma$-alumina catalyst submitted to in situ sulfiding, using sulfur powder as a sulfiding agent. It also seems useful to recall that passion fruit, tucuma and buriti oils were obtained by extraction of seeds with $n$-hexane in the laboratories of UFPA and did not undergo further refining. Rocha et al. ${ }^{39,40}$ presented a detailed discussion of their findings and some reactions schemes to illustrate their analyses. In this review, only some elements from their studies are considered. Tables 8 and 9 show some of the results obtained with buriti oil to estimate the influence of experimental parameters and with all the preceding oils to observe the role of the saturation degree of the fatty acid moieties as well as their chain length.

An increase in gas, cycloalkanes and aromatics production resulted from an increase in the reaction temperature from 360 up to $430^{\circ} \mathrm{C}$. In contrast, the quantities of linear alkanes and acids decreased. A higher hydrogen pressure during hydrocracking increased the production of linear alkanes essentially due to a better transformation of fatty acids formed in the first step of the cracking process. The amount of cycloalkanes obtained in this study is in contrast to the very high selectivity for linear alkanes obtained by Gusmão et al.,${ }^{17}$ which will be discussed below.

With the decrease in the saturation of the oil feed, a decrease in the alkane, as well as in the gas production, is observed. In contrast, the production of cycloalkanes and aromatics is favored. Although small differences appear in the case of acids and water production, these two types of

Table 8. Influence of hydrogen pressure and temperature in the hydrocracking of buriti oil on the product yields (wt.\%) of different hydrocarbons families. When varying temperature, initial hydrogen pressure was fixed at $14 \mathrm{MPa}$ and the reaction time was $1 \mathrm{~h}$. When varying hydrogen pressure, reaction temperature was kept at $360^{\circ} \mathrm{C}$ and the reaction time was $2 \mathrm{~h}$ (data from reference 39)

\begin{tabular}{lccccccc}
\hline \multirow{2}{*}{ Experimental parameters } & \multicolumn{5}{c}{ Products / wt.\% } \\
\cline { 3 - 8 } & & Gases & Alkanes & Cycloalkanes & Alkylbenzenes & Acids & Water \\
\hline Temperature & $360^{\circ} \mathrm{C}$ & 10.0 & 73.1 & 5.2 & 0.1 & 4.0 & 4.8 \\
Temperature & $430^{\circ} \mathrm{C}$ & 13.0 & 50.6 & 23.7 & 3.6 & 0.5 & 5.5 \\
Pressure & $7 \mathrm{MPa}$ & 7.0 & 48.0 & 11.4 & 0.3 & 28.0 & 3.0 \\
Pressure & $14 \mathrm{MPa}$ & 9.4 & 74.6 & 8.0 & 0.2 & 0.3 & 5.4 \\
\hline
\end{tabular}


Table 9. Yields (wt.\%) of product families after hydrocracking of vegetable oils. Reaction temperature was fixed at $360{ }^{\circ} \mathrm{C}$, the initial hydrogen pressure at $14 \mathrm{MPa}$ and the reaction time at $2 \mathrm{~h}$. The degree of saturation of fatty acid moieties decreases from tucuma to soybean oil (data from reference 40 )

\begin{tabular}{lcccccc}
\hline Oil feed & Gas & Alkanes & Cycloalkanes & Alkylbenzenes & Acids & Water \\
\hline Tucuma & 12.7 & 76.5 & 2.6 & 0.5 & 0.3 & 5.0 \\
Babassu & 12.5 & 76.8 & 2.9 & 0.2 & 0.5 & 5.1 \\
Buriti & 9.4 & 74.6 & 8.0 & 0.2 & 0.3 & 5.4 \\
Passion fruit & 9.2 & 65.3 & 13.2 & 4.1 & 0.6 & 5.6 \\
Soybean & 8.3 & 66.6 & 11.9 & 4.3 & 0.5 & 5.4 \\
\hline
\end{tabular}

products do not seem very dependent on the oil formula. The results in Table 9 suggest an incomplete hydrogenation of the $\mathrm{C}=\mathrm{C}$ bonds in the chosen experimental conditions, enabling new reforming pathways at the beginning or as a consequence of fatty acid liberation. The lower production of gas products is in part due to the fact that the results are given on a weight basis: for tucuma, compared for example to soybean oil, a same weight of oil means a greater number of oil molecules and therefore, the potential formation of a greater number of $\mathrm{CO}_{2}, \mathrm{CO}, \mathrm{C} 3, \ldots$ gaseous compounds, i.e. a greater yield of gases on a weight basis. Alternatively, the lower production of gases, with the less saturated feed, may result from differences in catalyst deactivation: the oils producing more cycloalkanes and aromatics compounds, known as coke precursors, would cause a higher deposition of coke on the catalyst and limit its hydrogenolysis properties. To go further in the interpretation of the results however, one needs a detailed gas phase analysis after different reaction times and also a fine determination of the surface composition of the catalyst, before and after reaction.

In order to discuss the differences between the results of Rocha et al. ${ }^{39,40}$ and those of Gusmão et al. ${ }^{17}$ it is important to recall that, besides small differences in experimental procedures and in the nature of the feeds, which may account for some difference in the product distribution, the catalysts used in both studies are different. The main difference could result from the mode of sulfiding, in situ sulfiding with initially solid but probably vapor sulfur during heating, ${ }^{39}$ and ex situ presulfiding with $\mathrm{H}_{2} / \mathrm{H}_{2} \mathrm{~S}$ mixture at $500{ }^{\circ} \mathrm{C} .{ }^{17}$ When examining the literature on hydrotreatment, it seems that these latter conditions are able to generate a better degree of sulfiding of the Mo and Ni active species than the former. The less sulfided NiMo/alumina catalyst of Rocha et al. ${ }^{39}$ could retain some metallic properties and allow the occurrence of reactions such as cyclisation and aromatization.

Whatever the complete interpretations of the observed facts, it is important to note that, depending on the saturation degree of the vegetable oils, depending on the chain length of the acidic moieties, and depending on the experimental conditions, different contents of alkanes, alkylcycloalkanes and alkylaromatics can be obtained.
Therefore, the important flexibility of the hydrocracking of triglycerides means that this reaction can be used to obtain liquid fuels, generally fully deoxygenated, useful either as additives to gasoline or as additives to diesel fuels.

\section{Final Discussion and Perspectives}

The amount of liquid fuels that agricultural raw materials can produce will never be enough to totally substitute petroleum fuels, nor will they be able to satisfy all human demands. However, these alternative liquid fuels can play a significant role in some particular situations, for example in distant areas from the petroleum refining units and in areas where storage may be a problem.

Before reaching a third generation of liquid biofuels, i.e. those obtained by liquefaction of wood and agriculture residues, special attention must be given to oily compounds (including those generated by algae), as was given to sugar cane and ethanol in the 1970s.

Since the 1990s in Brazil, a great number of studies have been devoted to the processes of transesterification of vegetable oils with methanol and to a lesser extent, ethanol, to produce so-called biodiesel. The present production in 2010 at industrial level has meant that it is possible to systematically use a B5 mixture, i.e. a fuel containing $95 \%$ petroleum diesel mixed with $5 \%$ biodiesel, and the projections for 2013 are planning the use of B20 mixtures, resulting in a significant increase in biodiesel production. This is fully realistic in areas of large liquid fuel consumption, but it does not provide a solution for regions where fuel distribution is difficult. In these areas it seems more interesting to directly produce the required quantity of liquid fuel. Besides transesterification and the development of universal engines which run on all types of fuel, another option is the pyrolysis and cracking reactions of vegetable oils and fats, although further development is needed for these to be used as a complete liquid fuel and not only an additive to existing fuels. In view of the results obtained up to now by uncatalysed cracking of triglycerides and related compounds, only thermocatalytic transformations seem to have a real future. 
With the present knowledge and published studies, it is suggested the use of catalysts with moderate acidity in order to obtain liquid fuels of the diesel type, and catalysts with stronger acidity to obtain substitutes for gasoline. However, a number of problems remain in this area and deserve attention.

Up to now, a limited number of studies deal with the aging of the catalysts used in the cracking of vegetable oils, and little seems to be known about their regeneration. In order to increase the lifetime of a catalyst, the first step is to achieve complete control of the quality of the feed. With vegetable oils and related compounds, the studies described above made use of refined and non refined reactants, in which compounds other than fatty acids moieties are present. In such feeds, besides the presence of some bulky molecules such as vitamins, $\beta$-carotene and a number of mineral impurities such as $\mathrm{P}, \mathrm{S}, \mathrm{Ca}$, traces of pesticides of very complex structures also exist. Such molecules, even though present only in the ppb and exceptionally in the ppm range are able to foul the catalytic active sites. The mineral elements can also be strongly adsorbed on the catalysts and modify the accessibility and/or the chemical state of the active sites. Understanding and quantifying catalyst deactivation during the thermocatalytic cracking of oils and fats would be very useful for the design of reactors and for defining the physical geometry of the catalyst and the disposition of the catalytic bed. As the precursors of the catalysts are always oxides, either pure or modified, studies to eliminate coke at the end of the reactions and allowing regeneration seem necessary.

In parallel to the study on used catalysts, more in depth knowledge of the composition of the used feeds is required, not only to get feedstocks of known and reproducible quality, but also to extract from them some of the molecules that may be useful in the fields of health and food such as vitamins A, E, carotenoïds, lecithins, or as a source of renewable and biodegradable reagents (fatty acids, fatty alcohols, glycerol). Generally, it appears that triglyceride hydrolysis in acidic medium, saponification and refining processes deserve renewed attention.

Coming back to the type of industrial process that can be used in the degradation of triglycerides, it seems important to obtain more data on the point of entry of the feed. An entry at the level of FCC reactor would probably be better for low molecular products, potential additives to gasoline. On the other hand, a rather high water concentration on the FCC catalysts might modify their acidity and alter their cracking properties. The input at the level of hydrotreating of heavy petroleum cuts, as done by PETROBRAS,${ }^{8}$ should lead to molecules with higher molecular weight, fully compatible with diesel type fuels. In this case, to know and control the impact of the oxygenated molecules on the sulfur content of the catalysts and on their lifetime is of fundamental importance. However, in this case attention must also be given to hydrogen consumption, due to the price of this reagent. A possible way to decrease hydrogen consumption, as mentioned before, could be finding catalysts where the decarboxylation and/or decarbonylation are optimized. A more systematic comparison between vegetables oils and fats and fatty acids hydrocracking is likely to suggest new catalysts for this problem.

Clearly, new studies have to be planned to obtain a complete understanding of the processes implied in the valorization of triglycerides and related compounds to produce liquid fuels. However, the progress seems rapid, and local and national policies can further accelerate it. A recent paper supports hydroprocessing of vegetable oils as an interesting option for diesel additive, ${ }^{41}$ whereas a very recent review described the state of art in using triglycerides and related feedstocks for production of clean hydrocarbon fuels. ${ }^{42}$

\section{Acknowledgements}

R. F. thanks Fundação de Amparo à Pesquisa do Estado da Bahia (FAPESB) for a fellowship during this study. This article was also written in memory of J. Gusmão.

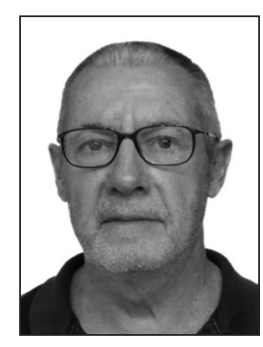

Roger Fréty graduated in Physical Chemistry at the University of Lyon 1 (France) where he also obtained his Doctorat d'Etat in 1969. He worked as a researcher at the Centre National de la Recherche Scientifique (CNRS, France) from 1967 to 2009 and maintained strong scientific relations with Brazil on the field of catalysis for many years. He is presently working at the Universidade Federal da Bahia (Bahia State, Brazil), as a visiting professor. His main scientific interests include gas-solid reactions/interactions, preparation and characterization of metal and sulfide catalysts and catalyst application to environmental and green chemistry.

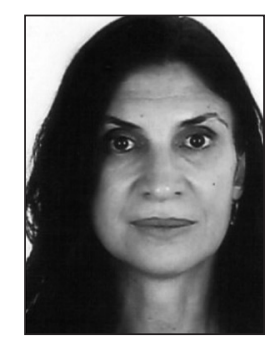

Maria da Graça M. Carneiro da Rocha graduated in Chemical Engineering at the Escola Politécnica of the Universidade Federal da Bahia (UFBA, Bahia State, Brazil). She received her MSc in Chemical Engineering from the Manhattan College (New York, USA) and PhD in 
Catalysis from the University of Lyon 1 (France) in 1995. She worked in research and process development at the Camaçari Petrochemical Complex and at the Centro de Pesquisa e Desenvolvimento (CEPED), both in Bahia State, Brazil. Maria was a postdoc at the Laboratoire de Chimie Appliquée à l'Environnement (LACE) in 2001 and at the Institut de Recherches sur la Catalyse et l'Environnement (IRCE) in 2002 (Lyon, France). She has been an Assistant Professor at the Chemistry Institute of the UFBA since 1997. Her main scientific interest is on heterogeneous catalysis, its application to environmental and green chemistry and catalyst characterization.

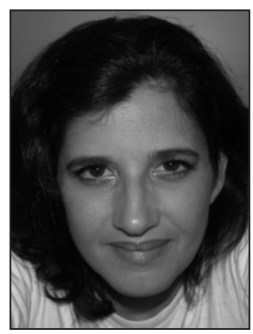

Soraia Brandão obtained her BSC in Chemical Engineering from the Universidade Federal da Bahia (UFBA, Bahia State, Brazil) in 1988 and the PhD from the University of Milan (Italy) in 1993. Soraia was a postdoc at the Institute of Catalysis and Petrochemical (ICP, Madrid) working with Prof. Pedro Ávila on the preparation of structured catalysts in 2002. She also joined Prof. Luca Lietti group as a postdoc at the Polytechnic University of Milan dedicated to experiments on thermoprogrammed surface reaction (TPSR) in 2003. She joined the UFBA Chemical Institute in 1995. Her research interests include heterogeneous catalysis focusing on the natural gas conversion for clean energy generation (catalytic combustion) and the hydrogen production and biomass conversion into more valuable products.

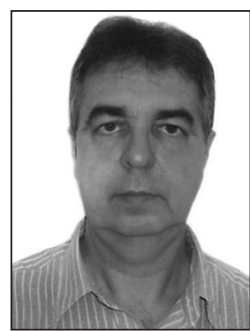

Luiz A. M. Pontes obtained his MSc from the Instituto Alberto Luiz Coimbra de Pós-graduação e Pesquisa de Engenharia/Universidade Federal do Rio de Janeiro (COPPE/UFRJ, Rio de Janeiro State, Brazil) in 1981 and his PhD from the University of Campinas (UNICAMP, São Paulo State, Brazil) in the area of Chemical Engineering in 1997. At present he is a Full Professor at the Universidade Salvador (Bahia State, Brazil), in which he leads the postgraduation, research and extension areas. He has been coordinating the North and North-East regional net for catalysis and teaching in a Joint Chemical Engineering PhD program between the Universidade Federal da Bahia and the Universidade Salvador since 1995. His research interests are oil and petrochemicals, focusing on catalysis, energy, environment, fuels quality and regulations in the oil and petrochemical industry.

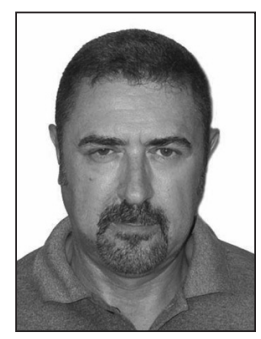

Jose Fernando Padilha obtained his BSc and MSc in Chemical Engineering from the Universidade Federal de São Carlos (São Paulo State, Brazil). He worked at the $R \& D$ Department of the COPENEPetroquímica do Nordeste S.A. (Bahia State, Brazil) from 1986 to 1996 and also at the Laboratory of Catalysis of the Universidade Salvador (Bahia State, Brazil) from 2001 to 2009. At present he is a researcher at the Instituto Brasileiro de Tecnologia e Regulação (IBTR, Brazil) and teaches at the Instituto Federal de Educação Tecnológica da Bahia. His research interests include zeolite synthesis and modification for application in the petroleum refining and petrochemicals production with special emphasis on hydrocarbon cracking.

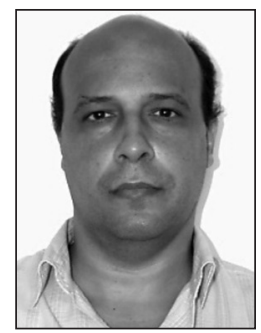

Luiz Eduardo P. Borges obtained his BSc degree from the Universidade Federal do Rio de Janeiro (Rio de Janeiro State, Brazil) and his MSc and DSc from the Universite Claude Bernard (Lyon 1, France). He joined the Chemical Engineering Department of the Instituto Militar de Engenharia (Rio de Janeiro State, Brazil) in 1997. His areas of research include heterogeneous catalysis, chemical reaction engineering and biomass conversion. He has published twenty research papers in various journals.

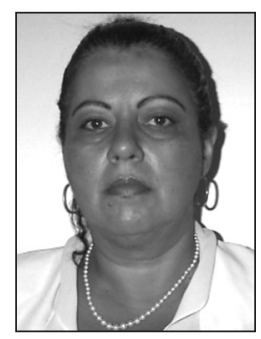

Wilma de Araujo Gonzalez graduated in Chemistry at the Fundação Técnico Educacional Souza Marques (FTESM, Rio de Janeiro State, Brazil) in 1977 and has obtained her MSc and PhD from the Chemical Engineering Department of the Instituto Militar de Engenharia (IME, Rio de Janeiro State, Brazil). She is presently working at the Chemical Engineering Department of the Military Institute of Engineering. Her areas of research include heterogeneous catalysis and biomass conversion into more valuable products.

\section{References}

1. Pinto,A. C.; Guarieiro, L. L. N.; Rezende, M. J.C.; Ribeiro, N. M.; Torres, E. A.; Lopes, W. A.; Pereira, P. A. P.; Andrade, J. B.; J. Braz. Chem. Soc. 2005, 16, 1313.

2. Suarez, P. A. Z.; Meneghetti, S. M. P.; Meneghetti, M. R.; Wolf, C. R.; Quim. Nova 2007, 30, 667. 
3. Suarez, P. A. Z.; Meneghetti, S. M. P.; Quim. Nova 2007, 30, 2068.

4. Silva, P. R. F.; Freitas, T. F. S.; Ciência Rural 2008, 38, 843.

5. Gonzalez, W. A.; Nunes, P. P.; Ferreira, M. S.; Martins, E. P.; Reguera, F. M.; Pastura, N. M. R.; Proceeding of the $3^{\circ}$ Encontro de Energia no Meio Rural, 2000, Campinas-SP, Brazil, 2003; available online at http://www.proceedings.scielo.br/scielo. php?script=sci_arttext\&pid=MSC0000000022000000200047 $\& \operatorname{lng}=$ en\&nrm=iso.

6. Pastura, N. M. P.; Nunes, P. P.; Gonzalez, W. A. In Biodiesel e Óleo Vegetal in Natura, Soluções Energéticas para a Amazônia; Barreto, E. J. F.; Correia, J. C.; Gonzalez, W. A., eds.; Ministério das Minas e Energia: Brasília, 2008, ch. 7. http://luzparatodos. mme.gov.br/luzparatodos/downloads/Solucoes_Energeticas_ para_a_Amazonia_Biodiesel.pdf.

7. Suarez, P. A. Z.; Santos, A. L. F.; Rodrigues, J. P.; Alves, M. B.; Quim. Nova 2009, 32, 768.

8. www2.petrobras.com.br/tecnologia/ing/hbio.asp accessed in April 2010.

9. www.uop.com/renewables/10010.html accessed in June 2010.

10. http://www.nesteoil.com/default.asp?path= 1,41,540,2384,7906,14097 accessed in June 2010.

11. www.biodieselmagazine.com/article.jsp?article_id=1481 accessed in June 2010.

12. Iki, H.; Iguchi, Y.; Koyama, A.; $16^{\text {th }}$ Saudi Arabia-Japan Joint Symposium, Dahran, Saudi Arabia, 2006; available online at http://www3.kfupm.edu.sa/catsymp/Symp16th/PDF\%20 Papers/05koyama.pdf.

13. Huber, G. W.; O’Connor, P.; Corma, A.; Appl. Catal., A 2007, 329, 120.

14. Maher, K. D.; Bressler, B. C.; Bioresour. Technol. 2007, 98, 2351.

15. Anjos, J. R. S.; Gonzalez, W. A.; Lam, Y. L.; Fréty, R.; Appl. Catal. 1983, 5, 299.

16. Nunes, P. P.; Brodski, D.; Bugli, G.; Djega-Mariadassou, G.; Rev. Inst. Français du Pétrole 1986, 41, 299.

17. Gusmão, J.; Brodski, D.; Djega-Mariadassou, G.; Fréty, R.; Catal. Today 1989, 5, 533.

18. Fernandes, M. A. G.; Pastura, N. M. R.; Lam, Y. L.; Anais do $3^{\circ}$ Seminário Brasileiro de Catálise, IBP, Salvador, Bahia, 1985.

19. Alencar, J. W.; Alves, P. B.; Craveiro, A. A. J.; J. Agric. Food Chem. 1983, 31, 1268.

20. Lima, D. G.; Soares, V. C. D.; Ribeiro, E. B.; Carvalho, D. A.; Cardoso, E. C. V.; Rassi, F. C.; Mundim, K. C.; Rubim, J. C.; Suarez, P. A.; J. Anal. Appl. Pyrolysis 2004, 71, 987.

21. Oliveira, E.; Quirino, R. L.; Suarez, P. A. Z.; Prado, A. G. S.; Thermochim. Acta 2006, 450, 87.
22. Doll, K. M.; Sharma, B. K.; Suarez, P. A. Z.; Erhan, S. Z.; Energy Fuels 2008, 22, 2061.

23. Suarez, P. A. Z.; Moser, B. R.; Sharma, B. K.; Erhan, S. Z.; Fuel 2009, 88, 1143.

24. Santos, A. L. F.; Martins, D. U.; Iha, O. K.; Ribeiro, R. A. M.; Quirino, R. L.; Suarez, P. A. Z.; Bioresour. Technol. 2010, 101, 6157.

25. Figueiredo, M. K. K.; Romeiro, G. A.; d'Avila, L. A.; Damasceno, R. N.; Franco, A. P.; Fuel 2009, 88, 2193.

26. Figueiredo, M. K. K.; Romeiro, G. A.; Damasceno, R. N.; J. Anal. Appl. Pyrolysis 2009, 86, 53.

27. Wiggers, V. R.; Meier, H. F.; Wisniewski Jr., A.; Barros, A. A. C.; Wolf Maciel, M. R.; Bioresour. Technol. 2009, 100, 6570.

28. Wiggers, V. R.; Wisniewski Jr., A.; Madureira, L. A. C.; Barros, A. A. C.; Meier, H. F.; Fuel 2009, 88, 2135.

29. Wisniewski Jr., A., Wiggers, V. R.; Simionatto, E. C.; Meier, H. F.; Barros, A. A. C.; Madureira, L. A. C.; Fuel 2010, 89, 563.

30. Anjos, J. R. S.; Lam, Y. L.; Fréty, R.; Bol. Téc. Petrobrás 1981, 24, 139.

31. Santos, F. R.; Ferreira, J. C. N.; Costa, S. R. R.; Quim. Nova 1998, 21, 560 .

32. Guerra, D. L.; Lemos, V. P.; Angelica, R. S.; Airoldi, C.; Eclética Química 2007, 32, 19; available online at http://www.scielo.br/ pdf/eq/v32n4/v32n4a03.pdf.

33. Reguera, F. M.; Araujo, L. R. R.; Picardo, M. C.; Bello, F. O.; Scofield, C. F.; Pastura, N. M. R.; Gonzalez, W. A.; Mater. Res. 2004, 7, 343.

34. Araujo, L. R. R.; Scofield, C. F.; Pastura, N. M. R.; Gonzalez, W. A.; Mater. Res. 2006, 9, 181.

35. Prado, C. M. R.; Antoniosi Filho, N. R.; J. Anal. Appl. Pyrolysis 2009, 86, 338.

36. Brandão, F. R.; Quirino, R. L.; Mello, V. M.; Tavares, A. P.; Peres, A. C.; Guinhos, F.; Rubim, J. C.; Suarez, P. A. Z.; J. Braz. Chem. Soc. 2009, $20,954$.

37. Quirino, R. L.; Tavares, A. P.; Peres, A. C.; Rubim, J. C.; Suarez, P. A. Z.; J. Am. Oil Chem. Soc. 2009, 86, 167.

38. Graça, I.; Ramoa Ribeiro, F.; Cerqueira, H. S.; Lam, Y. L.; Almeida, M. B. B.; Appl. Catal., B 2009, 90, 556.

39. Rocha Filho, G. N.; Bentes, M. H. S.; Brodski, D.; Djega-Mariadassou, G.; J. Am. Oil Chem. Soc. 1992, 69, 266.

40. Rocha Filho, G. N.; Brodski, D.; Djega-Mariadassou, G.; Fuel 1993, 72, 543.

41. Mikulec, J.; Cvengros, J.; Joríkova, L.; Banic, M.; Kleinova, A.; J. Cleaner Prod. 2010, 18, 917.

42. Kubičková, I.; Kubička, D.; Waste Biomass Valor. 2010, 1, 293.

Submitted: July 6, 2010

Published online: April 28, 2011 